Nebelyuk Nazariy. Effect of corvitin on changes in cytokin levels in the development of experimental bronchial asthma in combination with adrenaline miocardial damage. Journal of Education, Health and Sport. 2021;11(2):308-316. eISSN 2391-8306. DOI http://dx.doi.org/10.12775/JEHS.2021.11.02.029

https://apcz.umk.pl/czasopisma/index.php/JEHS/article/view/JEHS.2021.11.02.029

https://zenodo.org/record/5347996

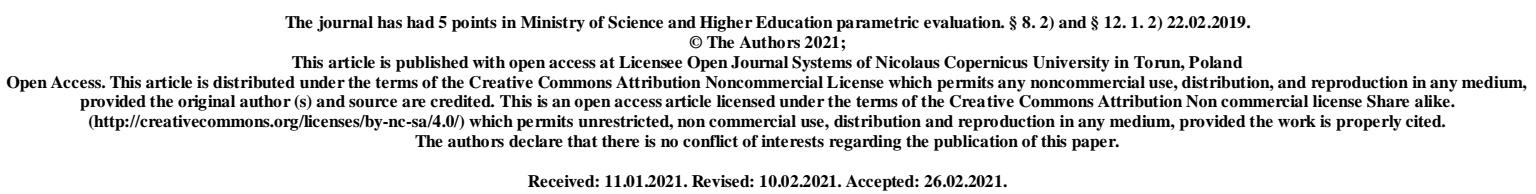

UDK: 616.248-092.419-06

\title{
EFFECT OF CORVITIN ON CHANGES IN CYTOKIN LEVELS IN THE DEVELOPMENT OF EXPERIMENTAL BRONCHIAL ASTHMA IN COMBINATION WITH ADRENALINE MIOCARDIAL DAMAGE
}

\author{
Nazariy Nebelyuk
}

\section{Danylo Halytskyi Lviv National Medical University}

Assistant Professor, Department of Pathological Physiology

\section{Abstract}

Bronchial asthma (BA) is a fairly common disease of the bronchopulmonary system. Its share is from 0.6 to $2 \%$ of all respiratory pathology, in different countries this pathology affects from 1 to $10 \%$ of the population, in general, the world has at least $2 \%$ of the total population.

Cardiovascular diseases continue to be a serious problem in medicine. The reason for this is a large number of stresses of various origins, which cause disruption of the body's adaptive capacity, the development of functional and structural changes in it, which ultimately lead to necrotic myocardial damage.

The problem of pathogenesis, early diagnosis and treatment of BA today is not fully understood, it is still one of the serious issues of modern medicine. Despite lengthy research, the serious costs of research, the participation of the world's leading experts, methods of 
prevention and treatment of cardiovascular diseases, and rehabilitation of patients remain imperfect, although some progress and serious results have already been achieved.

The aim of our study was to find out how cytokine levels will change at different stages of the formation of experimental asthma (EA) and adrenaline myocardial damage (AMD), what will be the indicators in the combination of these pathologies and what will be the effect of Corvitin on disorders combination of EA and AMD.

The study was conducted on 127 guinea pigs. Blood sampling was performed on the 1st, 4th, 18th and 25th days of EA development, on the same days in AMD, as well as in combination with EA with AMD, and on the 25th day of development of these diseases with treatment. Corvitin, the level of pro-inflammatory cytokines - tumor necrosis factor-alpha (TNF- $\alpha$ ) and interleukin-6 (IL-6) and anti-inflammatory - interleukin-10 (IL-10) was determined by solid-phase enzyme-linked immunosorbent assay.

Studies of cytokine levels in different groups of animals (intact, with EA, with AMD, with EA and AMD and in animals after treatment) showed that in animals with diseases, the rate of pro-inflammatory IL-6 and TNF- $\alpha$ increased with decreasing IL-10. At a combination of pathologies changes were the greatest that testifies to a course of diseases more difficult for an organism.

The use of Corvitin showed a positive effect on the violation of cytokine levels and their imbalance, which was due to its antioxidant, anti-inflammatory and immunomodulatory effects. Therefore, quercetin may be effective in the treatment of asthma or a combination of pathologies.

Key words: bronchial asthma; adrenaline myocardial damage; cytokine; tumor necrosis factor-alpha; interleukin-6; interleukin-10; Corvitin.

Bronchial asthma (BA) is a fairly common disease of the bronchopulmonary system [1]. Its share is from 0.6 to $2 \%$ of all respiratory pathology, in different countries this pathology affects from 1 to $10 \%$ of the population, in general, the world has at least $2 \%$ of the total population [1]. At the same time, these figures continue to increase.

Cardiovascular diseases continue to be a serious problem in medicine [2]. The reason for this is a large number of stresses of various origins, which cause disruption of the body's adaptive capacity, the development of functional and structural changes in it, which ultimately lead to necrotic myocardial damage. Stress is accompanied by the release of significant amounts of catecholamines into the blood and causes the development of hyperadrenalemia. 
Basically, adrenaline levels rise in the blood and myocardium under conditions of ischemia and hypoxia, all of which play an important role in the development of coronary heart disease, which is extremely common in today's conditions. [3].

The problem of pathogenesis, early diagnosis and treatment of asthma today is not fully understood, it is still one of the serious issues of modern medicine. Despite lengthy research, the serious costs of research, the participation of the world's leading experts, methods of prevention and treatment of cardiovascular diseases (CVD), and rehabilitation of patients remain imperfect, although some progress and serious results have already been achieved.

The aim of our study was to find out how cytokine levels will change at different stages of the formation of experimental asthma (EA) and adrenaline myocardial damage (AMD), what will be the indicators in the combination of these pathologies and what will be the effect of Corvitin on disorders combination of EA and AMD.

Cytokines are the most universal system for coordinating inflammatory and immune responses. As part of the body's immune response, it is cytokines that interact between nonspecific protective responses and specific immunity. In this case, the imbalance in the ratio of pro-inflammatory and anti-inflammatory pools in the disease can enhance the pathoimmune process and lead to cytokine-mediated tissue damage [4]. Corvitin was chosen because it has antioxidant, anti-inflammatory and immunomodulatory properties, has a cardioprotective effect in ischemic and reperfusion heart disease [5]. The active substance of Corvitin quercetin is part of various drugs used in the treatment of asthma and CV diseases.

\section{Materials and methods of research}

The study was conducted on 127 guinea pigs, which were divided into 14 experimental groups, 10 animals in the first and 9 animals in the other groups:

Group 1 - intact animals (control).

Group 2 - EA on the $1^{\text {st }}$ day.

Group 3 - EA on the $4^{\text {th }}$ day.

Group 4 - EA on the $18^{\text {th }}$ day.

Group 5 - EA on the $25^{\text {th }}$ day.

Group 6 - AMD on the $1^{\text {st }}$ day.

Group 7 - AMD on the $4^{\text {th }}$ day.

Group 8 - AMD on the $18^{\text {th }}$ day.

Group 9 - AMD on the $25^{\text {th }}$ day. 
Group 10 - EA and AMD on the $1^{\text {st }}$ day.

Group 11 - EA and AMD on the $4^{\text {th }}$ day.

Group 12 - EA and AMD on the $18^{\text {th }}$ day.

Group 13 - EA and AMD on the $25^{\text {th }}$ day.

Group 14 - EA and AMD after treatment with Corvitin on the $25^{\text {th }}$ day.

Experimental bronchial asthma was reproduced according to the method of Babich VI [6]. Previously, the animals were once sensitized with normal horse serum $(0.1 \mathrm{ml}$ intraperitoneally). For the next 3 consecutive days, $0.1 \mathrm{ml}$ of normal horse serum (NHS) with BCG killed in an autoclave (1 mg of BCG - $1.0 \mathrm{ml}$ of NHS) was injected subcutaneously. For the next 14 days, the guinea pigs were daily inhaled with $1.0 \mathrm{ml}$ of NHS per animal for 30 minutes in a tightly closed chamber using a nebulizer. Another inhalation was performed after 7 days, which led to the occurrence of experimental animals attack of bronchial asthma.

Acute adrenaline damage to the myocardium was simulated by a single intraperitoneal injection of $0.18 \%$ epinephrine hydrotartrate (Darnytsia, Ukraine) at a rate of $1 \mathrm{mg} / \mathrm{kg}$ by the method of Markova OO [7].

The drug Corvitin was administered from 16 to 25 days at a dose of $40 \mathrm{mg} / \mathrm{kg}$ intraperitoneally.

Blood sampling was performed on the $1^{\text {st }}, 4^{\text {th }}, 18^{\text {th }}$ and $25^{\text {th }}$ days of EA development, on the same days in AMD, as well as in combination with EA with AMD, and on the $25^{\text {th }}$ day of development of these diseases with treatment. The level of pro-inflammatory cytokines tumor necrosis factor-alpha (TNF- $\alpha$ ) and interleukin-6 (IL-6) and anti-inflammatory interleukin-10 (IL-10) was determined by solid-phase enzyme-linked immunosorbent assay [8].

The obtained results were processed according to the Student's method.

\section{Research results and their discussion}

At the first stage of research, the indicators for EA were determined.

On the $1^{\text {st }}$ day of the experiment there were no significant deviations in the level of the studied indicators.

On the 4th there was an increase in the level of TNF- $\alpha$ by $28.2 \%(\mathrm{P}<0.05)$ and the level of IL-6 by $23.3 \%$ (P <0.05), and the level of IL-10 decreased by $20,8 \%$ (P<0,05) against the first group of animals (Fig. 1).

In the later stages - on the $18^{\text {th }}$ and $25^{\text {th }}$ days of the experiment, the trend of the dynamics of indicators has not changed. On the $18^{\text {th }}$ day there was an even greater increase in 
the level of TNF- $\alpha$ - by $33.3 \%(\mathrm{P}<0.05)$ and a continuation of the increase in the level of IL-6 - by $26.6 \%(\mathrm{P}<0.05)$, there was also more reduction of IL-10 - by $25.5 \%(\mathrm{P}<0,05)$ (Fig. 1$)$.

On the $25^{\text {th }}$ day, the levels of TNF- $\alpha$ and IL- 6 further increased by $48.7 \%$ (P<0.05) and 28.3\% (P <0.05), respectively, the level of IL-10 was lower by 32, 9\% ( $<<0,05)$ relative to the control group (Fig. 1).

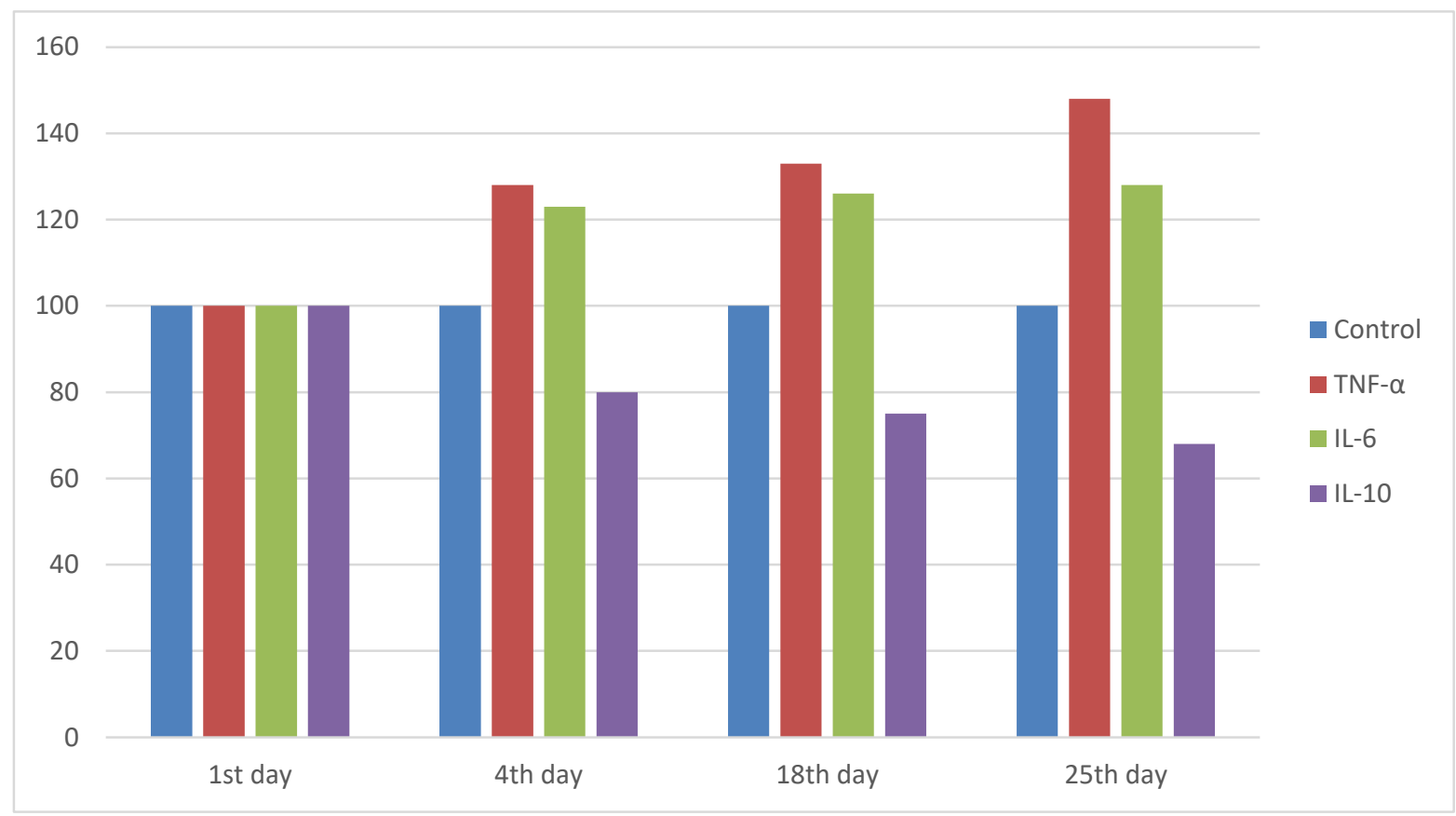

Fig.1. Features of changes in cytokines in the blood in the dynamics of EA (in \% of control)

At the second stage - at AMD changes of indicators had the same character as at EBA, the level of TNF- $\alpha$ and IL-6 increased, the indicator of IL-10 - decreased.

On the $1^{\text {st }}$ day, TNF- $\alpha$ increased by $38.4 \%$ (P <0.05), and IL-6 - by $30.0 \%(\mathrm{P}<0.05)$, the level of IL-10 decreased by $33.0 \%$ (P <0.05) (Fig. 2).

On the $4^{\text {th }}$ day, the indicators of TNF- $\alpha$ and IL- 6 increased by $33.3 \%(\mathrm{P}<0.05)$ and 26.6\% ( $\mathrm{P}<0.05$ ), respectively, IL-10 decreased by $23.0 \%$ ( $\mathrm{P}<0.05$ ) (Fig. 2).

On the $18^{\text {th }}$ day, TNF- $\alpha$ increased by $30.7 \%(\mathrm{P}<0.05)$ and IL- 6 by $25.0 \%(\mathrm{P}<0.05)$ and the level of IL-10 decreased by $22.0 \%<0.05$ ) (Fig. 2).

On the $25^{\text {th }}$ day of APM, the following changes were detected: increase in TNF- $\alpha$ by $28.2 \%(\mathrm{P}<0.05)$ and increase in IL-6 by $23.3 \%$ ( $\mathrm{P}<0.05)$, decrease in IL-10 by $34.0 \%$ ( $\mathrm{P}$ $<0.05)$ (Fig. 2).

During the third stage of the study, which was a combination of EA and AMD, the same changes were observed, but the deviation was more pronounced. 
On the $1^{\text {st }}$ day, there was an increase in TNF- $\alpha$ by $51.2 \%(\mathrm{P}<0.05)$ and an increase in IL-6 by $28.3 \%$ ( $\mathrm{P}<0.05)$, a decrease in IL-10 by $23.0 \%(\mathrm{P}<0,05)$ relative to the control group (Fig. 3).

On the $4^{\text {th }}$ day, TNF- $\alpha$ increased by $61.5 \%(\mathrm{P}<0.05)$, IL-6 - by $35.0 \%(\mathrm{P}<0.05)$, IL-10 decreased by $26.3 \%(\mathrm{P}<0.05)$ (Fig. 3).

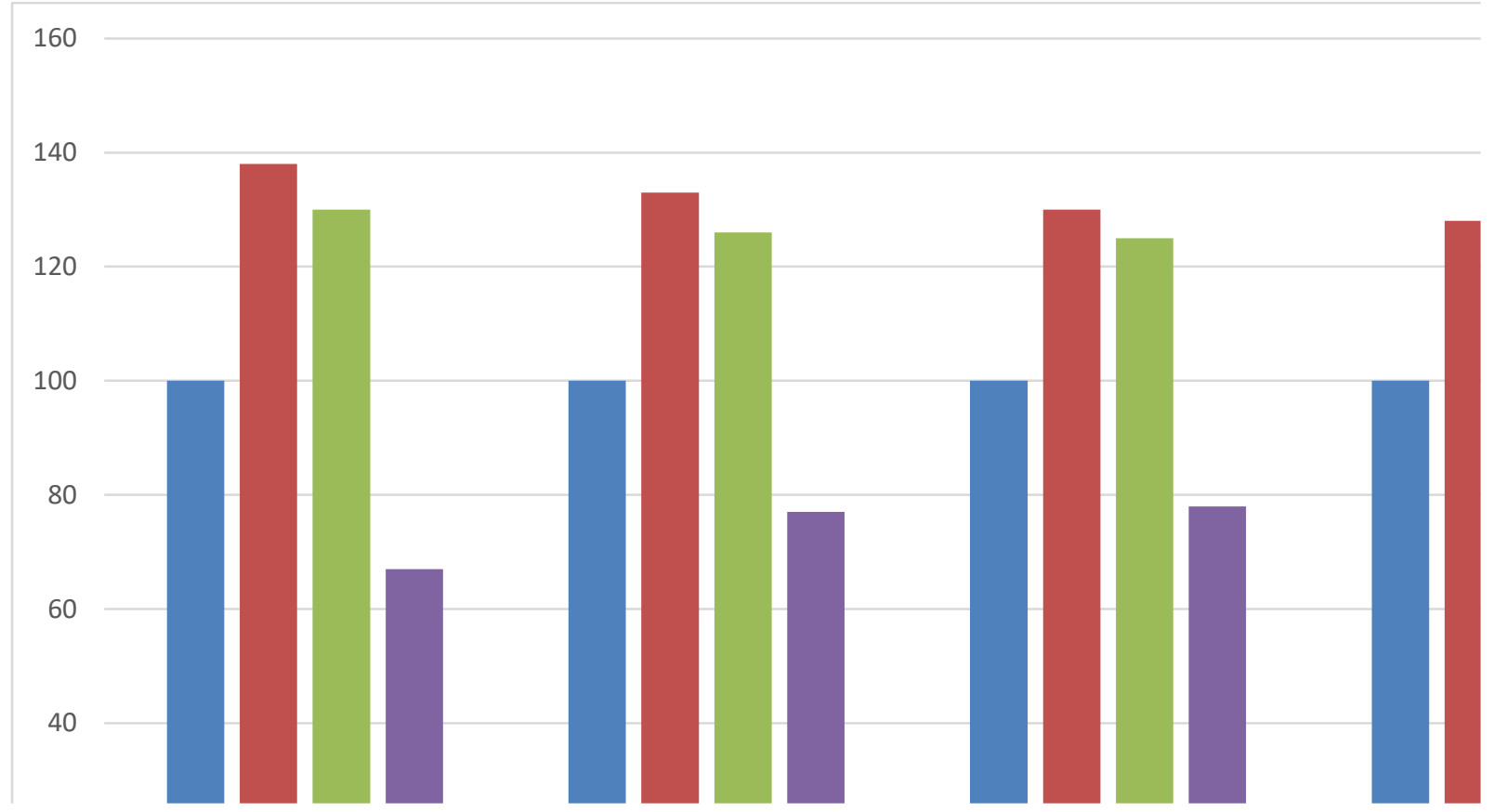

Fig. 2. Features of changes in the content of cytokines in the blood in the dynamics of AMD (in \% of control)

On the $18^{\text {th }}$ day, the increase in TNF- $\alpha$ and IL-6 was even more significant - by $66.6 \%$ $(\mathrm{P}<0.05)$ and $45.0 \%(\mathrm{P}<0.05)$, respectively, the decrease in IL-10 was $43.9 \%(\mathrm{P}<0.05)$ relative to the group of healthy animals (Fig. 3).

On the $25^{\text {th }}$ day, the changes were the largest for the entire study period. The level of TNF- $\alpha$ increased by $74.3 \%(\mathrm{P}<0.05)$, the increase in IL-6 was $65.0 \%$ ( $\mathrm{P}<0.05)$ compared with the control group, while the rate of IL-10 decreased by $47.2 \%$ (P <0.05) (Fig. 3).

At the last stage of the experiment, the effect of Corvitin on changes in the level of the studied cytokines was studied. Data obtained at day 25 in animals with a combination of EA and AMD treated were compared with the results of animals with a combination of these pathologies without treatment. 


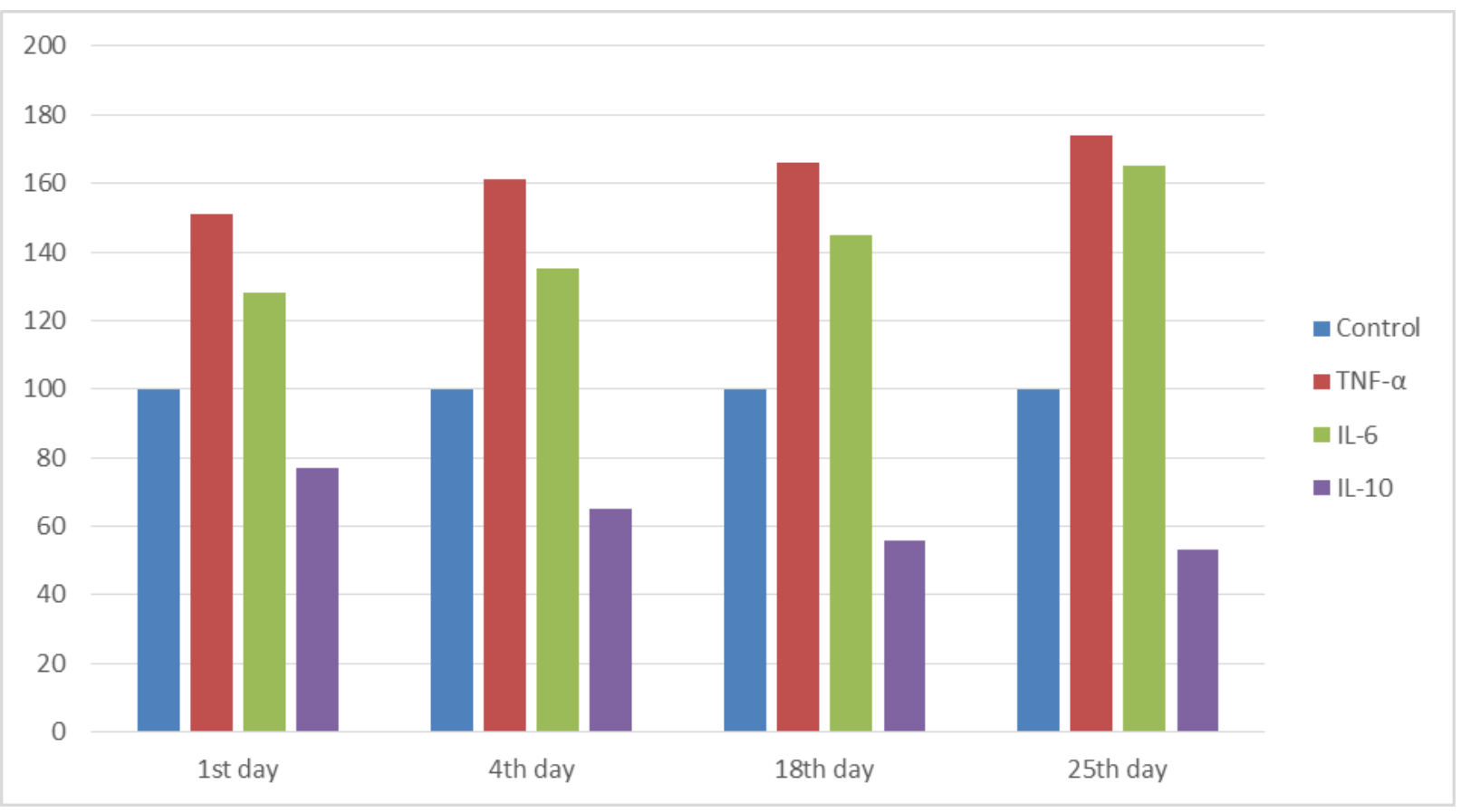

Fig. 3. Features of changes in the concentration of cytokines in the blood in the dynamics of EA and AMD (in \% of control)

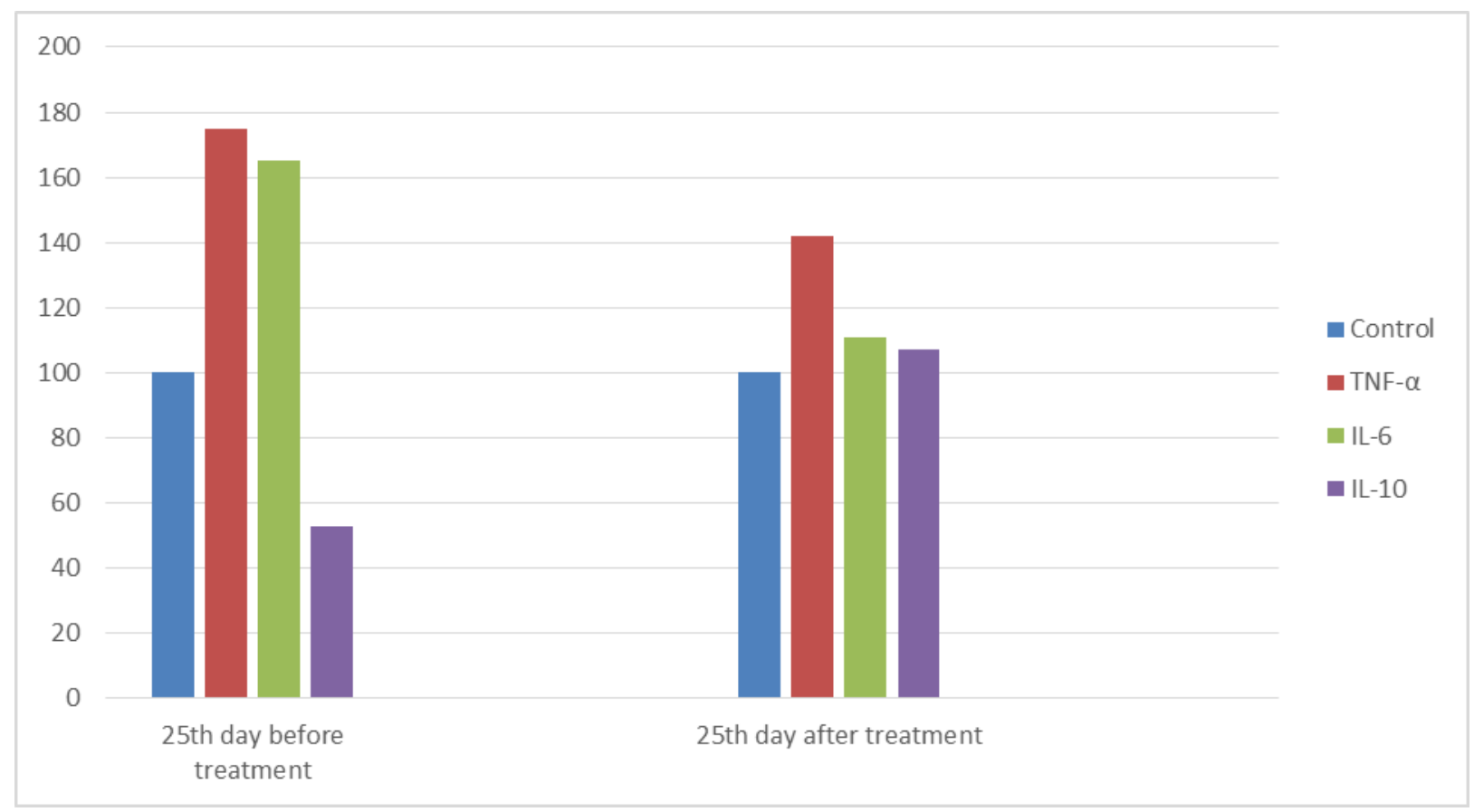

Fig. 4. The effect of Corvitin on blood cytokines in EA and AMD (in \% on the 25th day before and after treatment) 
According to the obtained results, a pronounced corrective effect of Corvitin on the studied indicators of the cytokine profile was revealed. The level of TNF- $\alpha$ decreased by $33.8 \%$ ( $\mathrm{P}<0.05$ ), and the result of the determination of IL- 6 showed a decrease of $49.4 \%$ (P $<0.05)$, while the level of IL-10 increased by $54.1 \%$ ( $\mathrm{P}<0.05)$ relative to the group of animals that were not administered the drug (Fig. 4).

\section{Conclusions}

Thus, studies of cytokine levels in different groups of animals (intact, with EA, with AMD, with EA and AMD and in animals after treatment) proved that in animals with diseases the rate of pro-inflammatory IL- 6 and TNF- $\alpha$ increased with decreasing IL -10 . Thus at EBA changes were most expressed on the 25th day of experiment, and at AMD - on the 1st day. At a combination of pathologies changes were the greatest that testifies to a course of diseases more difficult for an organism.

The use of Corvitin showed a positive effect on the violation of cytokine levels and their imbalance, which was due to its antioxidant, anti-inflammatory and immunomodulatory effects, and its cardioprotective effect is also important. Therefore, quercetin may be effective in the treatment of asthma or a combination of pathologies.

\section{References}

1. Regeda MS Bronchial asthma / MS Regeda // Monograph. Fifth reissue. - Lviv, 2012. - P. 8-9

2. Kovalenko VM Myocarditis: modern aspects of pathogenesis and diagnosis / VM Kovalenko // Ukr. rheumatism. magazine. - 2001. - № 1. - P. 18-22.

3. Susla OB Age-related changes in metabolism in the heart muscle of rats in the dynamics of adrenaline myocardial infarction / OB Susla // Med.himiya. - 2004. - V. 6, № 1. P. 41-47.

4. Clinical immunology and allergology (manual for practical classes) / V. Chopyak and others. Lviv: Publisher Tetyuk TV, 2015. 207 p.

5. Regulatory documents of the Ministry of Health of Ukraine https://mozdocs.kiev.ua/likiview.php?id=8711

6. Babich VI Modification of the method of experimental model of bronchial asthma in guinea pigs / VI Babich // Problems of pathology in experiment and clinic. - Lviv, 1979. Vol.3. - P. 159. 
7. Markova OO Myocardial dystrophy and reactivity of the organism / OO Markova // - Ternopil: Ukrmedknyha, 1998. - 152 p.

8. Dugarova ID On the role of cytokines in bronchial asthma. Pulmonology. 2009. №4. Pp. 96-102.

9. Ethics of the doctor and human rights: provisions on the use of animals in biomedical experiments // Experimental and clinical physiology and biochemistry. - 2003. V. 22, № 2. - P. 108-109. 